\title{
The hybrid palatoplasty: A preliminary report
}

\author{
David A Gillett MB BS FRACS, Howard M Clarke MD PHD FRCSC FAAP FACS \\ Division of Plastic Surgery, The Hospital for Sick Children and the Division of Plastic \\ Surgery, Department of Surgery, University of Toronto, Toronto, Ontario
}

DA Gillett, HM Clarke. The hybrid palatoplasty: A preliminary report. Can J Plast Surg 1996;4(3):157-160. A composite technique was developed for repair of the complete unilateral cleft palate. Using a Veau type pushback on the cleft side simplified anterior closure, and the cleft hemipalate was lengthened. A von Langenbeck procedure on the noncleft side minimized anterior raw area and provided a stable point for fixation. Fourteen consecutive patients with unilateral complete cleft palate underwent hybrid palatoplasties. There were no significant intra- or postoperative complications. No differences in speech development have been noted. The procedure was no more difficult than either of the standard procedures and offers technical and theoretical benefits.

Key Words: Hybrid, Palate repair, Pushback, von Langenbeck

\section{Palatoplastie hybride : rapport préliminaire}

RÉSUMÉ : Une technique composite a été mise au point pour réparer la fissure palatine unilatérale complète. À l'aide d'une technique adaptée de la méthode de Veau, la fermeture antérieure a été simplifiée sur le côté de la fissure, puis l'hémipalais a été allongé. L'intervention de von Langenbeck du côté non fissuré a minimisé la zone antérieure brute et offert un point stable pour la fixation. Quatorze patients consécutifs présentant une fissure palatine complète unilatérale ont subi des palatoplasties hybrides. Aucune complication per- ou post-opératoire significative n'a été notée. Aucune différence n'a été notée sur le plan du développement du langage. Cette intervention n'a pas été plus difficile que l'une ou l'autre des interventions classiques et offre des avantages sur les plans technique et théorique.

A method for the repair of the complete unilateral cleft palate is presented. This technique combines elements of both the von Langenbeck and pushback type palatoplasties. Therefore this procedure is called the 'hybrid' palatoplasty. Also reported are preliminary results on the first 14 consecutive patients to undergo this procedure.

\section{PATIENTS AND METHODS}

At The Hospital for Sick Children, Toronto, Ontario, cleft lip repair is performed at three months of age, and the palate is repaired at 12 months of age. In view of the findings of Ross (1), which demonstrated a significant reduction in anterior facial growth when primary alveolar surgery is performed, the alveolar cleft remains open until alveolar bone grafting at approximately nine to 10 years of age. 
Between March 1989 and October 199314 patients underwent the hybrid palatoplasty. All patients had unilateral complete clefts of the primary and secondary palates, but were otherwise healthy and nonsyndromal. All surgery was performed by a plastic surgical trainee or fellow under the direct supervision of the senior author or by the senior author. Postoperative follow-up ranged from 19 to 74 months (mean 37 months).

Nine male and five female patients were included in the series, giving a male:female ratio of 1.8:1, similar to the slight male preponderance reported in most series $(2,3)$. Five of the 14 patients had a positive family history of clefts of the lip or palate. Nine clefts were left-sided and five right-sided, demonstrating the usual predilection for the left side (2-4).

Surgery was scheduled for 12 months of age in all cases; however, one patient had surgery postponed for three months because of an upper respiratory tract infection. The average age at surgery was 12.2 months. Average weight at surgery was $9.5 \mathrm{~kg}$.

\section{TECHNIQUE}

In the unilateral complete cleft of the primary and secondary palates the palate on the cleft side is narrower and frequently shorter than on the noncleft side (5). To allow lengthening of the cleft side of the palate to obtain a symmetrical velum, a Veau type pushback procedure was used (Figure 1). This facilitated anterior closure which can be difficult to achieve using a von Langenbeck repair due to the anterior attachment of the bipedicled flaps. To minimize the size of the residual alveolar fistula the Veau type flap is elevated anteriorly as far as possible, without extending onto the alveolar ridge, to include the entire rugous mucoperiosteum in the flap. On the noncleft side, to avoid the increased anterior raw area associated with a pushback type flap, a von Langenbeck type procedure was used (Figure 2). The bipedicled flap on the noncleft side also provides a more stable point for fixation of the tip of the Veau type pushback flap and allows the tip to be secured as far anteriorly as possible, thus reducing the size of the obligatory alveolar fistula. Further, this helps to reduce the remaining raw area on the cleft side (Figure 3).
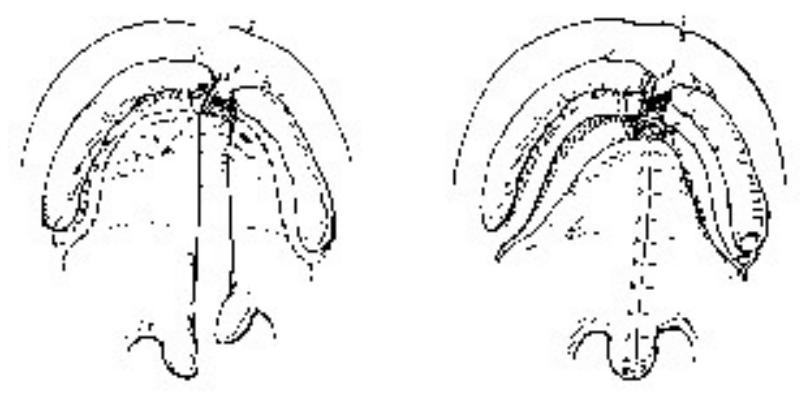

Figure 1) The Veau palatoplasty offers easy closure of the cleft but leaves a large raw area anteriorly and no point of fixation for the tips of the flaps 

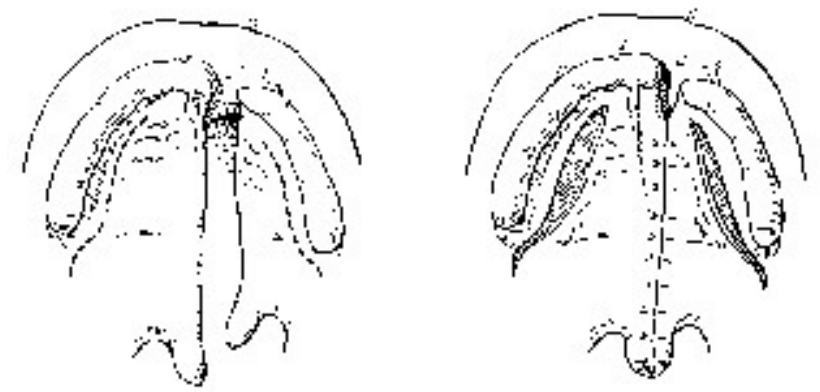

Figure 2) The von Langenbeck palatoplasty requires less dissection and allows stable fixation but does not permit lengthening of the cleft hemipalate
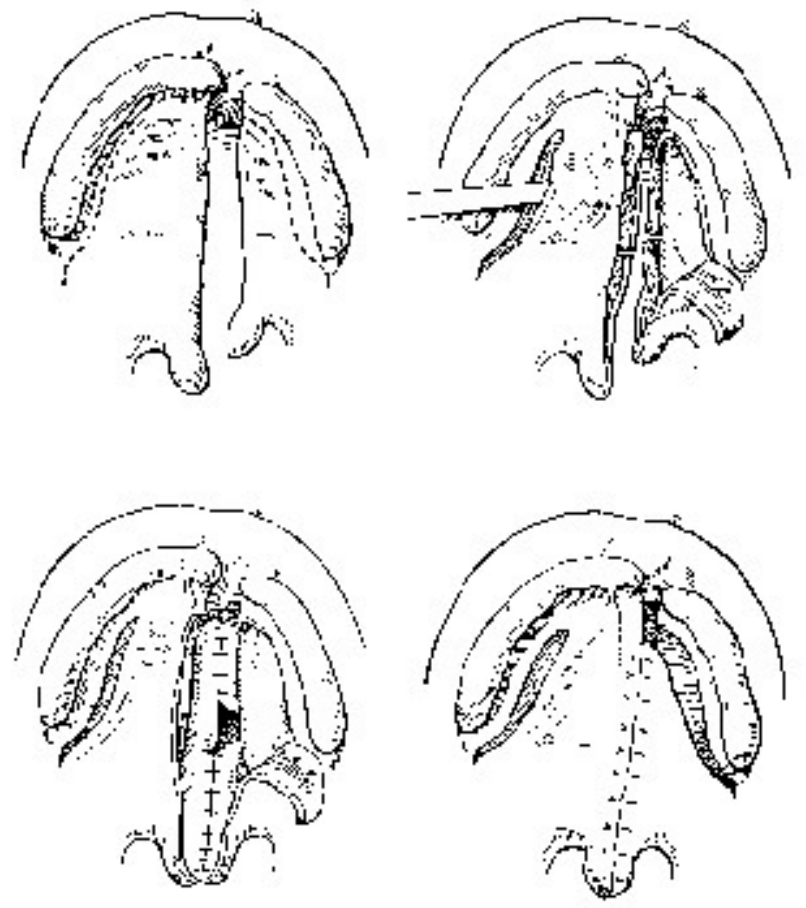

Figure 3) The hybrid palatoplasty. The incisions are planned asymmetrically to allow for lengthening of the cleft side (top left). Both flaps are elevated with the back cut on the cleft side allowing for lengthening (top right). The nasal side is closed leaving a defect on the cleft side (bottom left). Final closure allows secure fixation anteriorly and equal length of the two sides of the palate (bottom right) 
Nasal closure is obtained with a superiorly based vomerine flap extending the length of the vomer's attachment to the hard palate. This flap is sutured to the mobilized nasal mucosa of the cleft side. Submucoperiosteal elevation of the vomerine flap ceases as soon as a tension-free nasal layer closure can be attained. A back cut in the nasal mucosa on the cleft side allows lengthening of the hemipalate to equal that on the noncleft side. The back cut is positioned anteriorly over the hard palate to reduce the chance of secondary shortening of the palate because of scar contracture on the nasal surface of the palate.

The insertion of the palatal musculature into the posterior border of the hard palate is carefully freed from the bone and retropositioned (6); further mobilization around the greater palatine foramina allows easy approximation of the flaps. Having mobilized the flaps, closure is performed in three layers using absorbable mattress sutures.

\section{RESULTS}

Fourteen children have undergone hybrid palatoplasty, and there have been no significant intraoperative complications. Operative time, measured from entry in the operating room to exit, ranged from 95 to 190 mins (average 120 mins). Eleven of the 14 children also underwent otolaryngological examination, with 10 requiring insertion of ventilating tubes under the same anesthetic.

All procedures were without significant perioperative complications. Hospital stay ranged from three to six days (average four days, ie, home on the morning of the third postoperative day). To date no oronasal fistulae have been noted other than the planned alveolar fistula which remains open until closure at the time of bone grafting.

Follow-up ranges from 19 to 74 months (mean 37 months). To date there have been no detectable differences in speech development compared with similar children undergoing either standard von Langenbeck or pushback type palatoplasties. However, it must be stressed that this is a preliminary report of this technique, and considerably longer follow-up will be required before any realistic statements can be made regarding either speech development or facial growth. A longitudinal review of these patients is being undertaken and will be reported once a sufficient period of follow-up has passed.

\section{DISCUSSION}

A recent international survey of cleft palate and craniofacial units found one stage palatoplasty to be the preferred procedure in $76 \%$ of units (7). The von Langenbeck and Veau-Wardill type repairs were the most frequently performed, in almost equal numbers and accounting for $70 \%$ of all repairs. We have used a combination of the two techniques for repair of the palatal cleft in all children with complete unilateral clefts of the primary and secondary palates presenting in the senior author's practice since 1989 . We believe this approach optimizes the benefits of each repair technique, while minimizing the respective weaknesses.

In 1826 Johann Dieffenbach (8), the chief of surgery at the University of Berlin, published his use of lateral releasing incisions combined with lateral osteotomies through 
the hard palate for the repair of clefts of the hard palate. His successor at the University of Berlin, Bernhard von Langenbeck (9), in 1859 modified Dieffenbach's palate repair. He used similar lateral releasing incisions but, rather than osteotomizing the palatal bones, he elevated mucosal flaps at the subperiosteal level to enable the edges of the cleft to be sutured in the midline (Figure 2).

In 1922 Veau and Ruppe (10) divided the bipedicled mucoperiosteal flaps anteriorly thus creating unipedicled mucoperiosteal flaps, based on the greater palatine vessels which could be retropositioned to lengthen the soft palate (Figure 1). Veau believed that by lengthening the palate he would obtain superior speech results. Veau also lined the nasal surface of the repair with a vomerine flap to minimize cicatrization on the nasal surface of the palate. Kilner (11) and Wardill (12), working independently in England in 1937, further modified the technique by incorporating a ' $\mathrm{V}-\mathrm{Y}$ ' advancement anteriorly.

To provide further lengthening of the palate and to prevent secondary shortening on the nasal surface of the palate, Millard (13) modified the pushback palatoplasty by adding a mucoperiosteal island flap that was then inserted into the nasal release.

However, careful review of these patients revealed partial obliteration of the palatal vault and an increased incidence of anterior crossbite (14). In 1992 Millard et al (15) described combining the von Langenbeck and Wardill-Kilner type repairs for certain palatal clefts. In these children the alveolar cleft and the anterior hard palate cleft had been closed already. He uses this combination in approximately $3 \%$ of cases; where there is a round or blunt defect anteriorly the Wardill-Kilner type flap is used on the noncleft side and where there is a marked discrepancy in the length of the two halves of the palate, the pushback type procedure is used on the shorter side.

Lindsay and Witzel (5) reported an increased incidence of anterior crossbite in patients treated with the pushback type procedure compared with patients undergoing von Langenbeck repairs. In this and other studies (16-18), it was felt that the size of the anterior raw area was responsible for the growth disturbance. In view of these findings we have attempted to reduce the amount of anterior raw area.

When evaluating the results of palatoplasty we must consider both facial growth and speech development. Any technique that aims to minimize the amount of anterior raw area to reduce growth disturbance must be able to do so without adversely affecting speech development.

Several authors have examined the importance of palatal lengthening at primary palatoplasty. A study by Witzel et al (19) comparing pushback and von Langenbeck palatoplasty patients demonstrated no difference in either velopharyngeal closure pattern or conversational speech between the two groups. Holtmann et al (20) also found no difference in speech development comparing patients with and without primary palatal lengthening. Several authors have demonstrated the importance of freeing and retropositioning the levator muscles which are abnormally inserted into the posterior edge of the hard palate $(6,21)$.

On consideration of the history of the development of cleft palate surgery and the available clinical research we believe that maxillary growth disturbance and anterior dental crossbite are directly related to the amount of anterior raw area and primary alveolar surgery. We therefore minimize these factors in the hybrid palatoplasty by using a von Langenbeck flap on the noncleft side and delaying closure of the alveolar cleft until 
the time of alveolar bone grafting. Furthermore, speech development is related to careful freeing and retropositioning of the abnormally inserted levator muscles and not necessarily primary palatal lengthening. In the hybrid palatoplasty the palate is not lengthened overall, but the cleft side is mobilized to obtain a symmetrical velum. We carefully free the abnormally inserted levator muscles from their abnormal insertion, retroposition them and suture them in the midline.

\section{CONCLUSIONS}

This preliminary review of the first 14 patients to undergo this procedure demonstrates no increase in morbidity using the hybrid palatoplasty. The procedure is technically no more difficult than either Veau or von Langenbeck repairs. We believe that the combination of these popular and time-tested repairs precisely addresses the requirements of the unilateral complete cleft palate and minimizes the potential problems of each type of repair.

ACKNOWLEDGEMENTS: We thank Dr WK Lindsay for his advice and assistance and $\mathrm{Mr} \mathrm{Kam} \mathrm{Yu}$ for the artwork.

\section{REFERENCES}

1. Ross RB. Treatment variables affecting facial growth in complete unilateral cleft lip and palate. Part 3: Alveolus repair and bone grafting. Cleft Palate J 1987;24:33-44.

2. Fogh-Andersen P. Inheritance of Harelip and Cleft Palate:

Contribution to the Elucidation of the Etiology of the Congenital Clefts of the Face. Copenhagen: Nyt Nordisk Forlag, Arnold Busck, 1942:266.

3. Wilson MEAC. A ten-year survey of cleft lip and cleft palate in the south west region. Br J Plast Surg 1972;25:224-8.

4. Fraser FC. The genetics of cleft lip and cleft palate. Am J Hum Genet 1970;22:336-52.

5. Lindsay WK, Witzel MA. Cleft palate repair: Von Langenbeck technique. In: Bardach J, Morris HL, ed. Multidisciplinary Management of Cleft Lip and Palate. Philadelphia:

WB Saunders Company, 1990:303-8.

6. Braithwaite F, Maurice DG. The importance of the levator palati muscle in cleft palate closure. Br J Plast Surg 1968;21:60-2.

7. Huebner DV, Marsh JL, Barzilai J. The first 18 months of life:

A management protocol for cleft care. Pittsburgh: The American Cleft PalateCraniofacial Association Fiftieth Anniversary Meeting, April 21-24, 1993.

8. Dieffenbach JF. Beiträge zur Gaumennath. Litt Ann Ges Heilk 1826;6:305-14.

9. Langenbeck B. Die Uranoplastik mittelst Ablösung des mucös-periostalen Gaumenüberzuges. Arch Klin Chir 1861;2:205-87.

10. Veau V, Ruppe C. Technique de l'urano-staphylorraphie. J de Chir (Paris) 1922;20:113-44.

11. Kilner TP. Cleft lip and palate repair technique. St Thomas's Hosp Lond Eng Rep 1937;2:127-40.

12. Wardill WEM. The technique of operation for cleft palate. Br J Surg 1937;25:117-30. 
13. Millard DR. The island flap in cleft palate surgery. Surg Gynecol Obstet 1963;116:297-300.

14. Millard DR. Cleft Craft: The Evolution of Its Surgery. III Alveolar and Palatal Deformities. Boston: Little, Brown and Co, 1980:1211.

15. Millard DR, Flynn W, Rao MP. Combining the von Langenbeck and the WardillKilner operations in certain clefts of the palate. Cleft Palate Craniofac J 1992;29:85-6. 16. Kremenak CR, Huffman WC, Olin WH. Growth of maxillae in dogs after palatal surgery: I. Cleft Palate J 1967;4:6-17.

17. Bardach J, Salyer KE. Surgical Techniques in Cleft Lip and Palate. Chicago: Year Book Medical Publishers, Inc, 1987:272.

18. Randall P, LaRossa D. Cleft palate. In: McCarthy JG, ed. Plastic Surgery. Philadelphia: WB Saunders Company, 1990:2723-52.

19. Witzel MA, Clarke JA, Lindsay WK, Thomson HG. Comparison of results of pushback or von Langenbeck repair of isolated cleft of the hard and soft palate. Plast Reconstr Surg 1979;64:347-52.

20. Holtmann B, Wray RC, Weeks PM. A comparison of three techniques of palatorrhaphy: Early speech results. Ann Plast Surg 1984;12:514-8.

21. Kriens O. The anatomy of intravelar veloplasty. Broadbeach, Australia: 7th International Congress on Cleft Palate and Related Craniofacial Anomalies, October 31November 5, 1993. 